\title{
Use of Molecular Markers in the Management of Citrus Germplasm Resources
}

\author{
Robert R. Krueger \\ U.S. Department of Agriculture-Agricultural Research Service, National Clonal Germplasm Repository \\ for Citrus and Dates, 1060 Martin Luther King Boulevard, Riverside, CA 92507 \\ Mikeal L. Roose \\ Department of Botany and Plant Sciences, University of California, Riverside, CA 92521
}

ADDITIONAL INDEX WORDS. ISSR, apomixis, embryony

\begin{abstract}
New potential citrus germplasm accessions may be received as seed rather than budwood, thereby reducing phytosanitary risks. However, trueness-to-type may be an issue with seed materials because many varieties produce both apomictic (nucellar) and sexual (zygotic) embryos and most citrus is fairly heterozygous. To identify nucellar seedlings of polyembryonic types and to retain these as representing the type, we screened 1340 seedlings from 88 seed sources for markers amplified with two inter-simple sequence repeat (ISSR) primers. Sixteen seed sources produced no seedlings classified as being of nucellar origin. Among the remaining seed sources, seedlings classed as nucellar were identified for potential addition to the collection. In 37 accessions, both nucellar and zygotic seedlings were detected, and in some cases both types were retained. Inclusion of established accessions of the same cultivar group in the analysis allowed an initial assessment of similarity to existing accessions. This technique improved the efficiency of acquiring new germplasm of polyembryonic types by seed. The method identifies those seed sources that produce few or no nucellar seedlings, but it is not useful for determining which seedlings of monoembryonic types should be retained in collections.
\end{abstract}

Cultivated since ancient times in its center of origin in southeastern Asia, citrus production has spread over the centuries into most areas that have a suitable climate (Webber et al., 1967). Today citrus is one of the most widely cultivated fruit in the world, and most major production areas are far removed from the original area. Governments and academic institutions working to improve citrus production have established $e x$-situ collections of citrus germplasm to support breeding programs and other research efforts. Establishment and expansion of these collections has involved the introduction of new citrus germplasm accessions from other countries.

New accessions of citrus germplasm can be introduced either as budwood or seed. Introduction as budwood ensures trueness to type, but increases the risk of introducing exotic diseases or pathogen isolates because many important diseases of citrus are graft-transmissible (Frison and Taher, 1991; Timmer et al., 2000). Because of this, citrus germplasm cannot normally be released to users without undergoing an extensive indexing and therapy program. The risk of introducing exotic diseases is less with seeds, because no citrus diseases have been definitively proven to be seed-transmissible (Timmer et al., 2000). Exchange of citrus germplasm by seed is therefore less regulated than exchange by budwood. However, there are some disadvantages or complications to the introduction of citrus germplasm by seed. Some of these complications are due to juvenility factors inherent in all seedlings while others are due to the breeding system and reproductive characteristics of citrus.

Some groups of citrus produce seeds having both sexual

Received for publication 3 Jan. 2003. Accepted for publication 11 July 2003. The authors acknowledge and thank Osman Gulsen and Lisa Mu for their assistance with the ISSR analysis, and Noelle Barkley, Sabeena Singh, Kimberly Hurd, and Christina Caro for DNA extraction. Mention of a trademark, proprietary product, or vendor does not constitute a guarantee or warranty of the product by the United States Dept. of Agriculture nor the University of California and does not imply its approval to the exclusion of other products or vendors that may also be suitable. (zygotic) and asexual (nucellar) embryos, while other groups produce only zygotic embryos (Soost and Roose, 1996). In genotypes having nucellar embryony, seeds frequently contain multiple nucellar embryos that may be accompanied by a fully developed zygotic embryo. The presence of multiple embryos (polyembryony) is therefore taken to indicate the presence of nucellar embryony. Polyembryonic types will produce a certain percentage of nucellar seedlings that are genetically identical to the mother plant and will produce a phenotypically similar tree. The percentage of nucellar embryos varies with the variety, and seedling populations of these types have traditionally been planted out, evaluated, and selected (Soost and Roose, 1996). Because of juvenility factors, this approach has traditionally been a long-term enterprise that is resource-intensive. Monoembryonic varieties produce only sexual seedlings. Citrus hybridizes rather freely between species and sometimes between genera (Soost and Roose, 1996). Seed introduction of monoembryonic types will thus result in the introduction of small populations that will not be genetically identical to the mother plant nor to each other and may not resemble the mother plant phenotypically. Monoembryonic types introduced as seed may thus increase the amount of genetic diversity present but will not result in the introduction of a specific genotype.

Molecular markers have undergone great development in the last decade and are now routinely used in the management of germplasm collections (Bretting and Widrlechner, 1995; FordLloyd et al., 1997). Some of the uses cited include identification of redundancies and gaps in the collection, correction of misidentified accessions, assessing the actual genetic diversity present in the collection and genetic drift over time, and enhancement of germplasm accessions. The majority of reports in the literature deal with the assessment of the diversity present in a collection rather than management per se. Most of these examples were derived from seed-propagated crops that are stored as seed. Management of clonally propagated crops, such as citrus, is different in that collections are generally smaller than for seed 


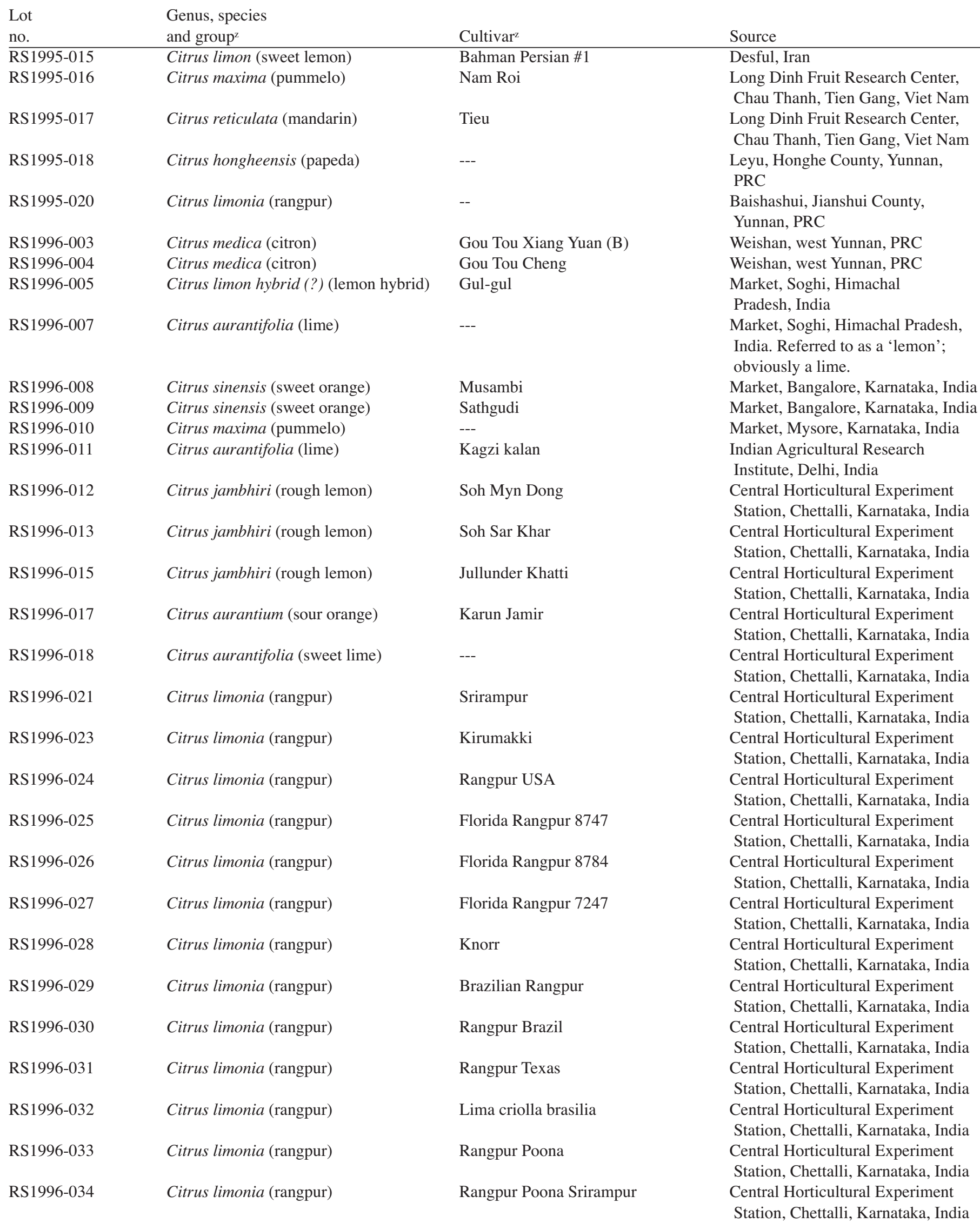




\begin{tabular}{|c|c|c|c|c|c|}
\hline \multicolumn{6}{|c|}{ Seedlings } \\
\hline Received & Germinatedy & Nucellar & Zygotic & $\begin{array}{l}\text { Nucellar } \\
\text { retained }\end{array}$ & $\begin{array}{l}\text { Zygotic } \\
\text { retained }\end{array}$ \\
\hline 5 & 3 & 3 & 0 & 1 & 0 \\
\hline 50 & 10 & 0 & 10 & 0 & 10 \\
\hline 50 & 3 & 2 & 1 & 1 & 1 \\
\hline 20 & 3 & 0 & 3 & 0 & 3 \\
\hline 50 & 18 & 18 & 0 & 1 & 0 \\
\hline 20 & 4 & 0 & 4 & 0 & 4 \\
\hline 50 & 20 & 0 & 20 & 0 & 15 \\
\hline 30 & 24 & 24 & 0 & 1 & 0 \\
\hline 15 & 3 & 3 & 0 & 1 & 0 \\
\hline 15 & 4 & 4 & 0 & 1 & 0 \\
\hline 15 & 6 & 6 & 0 & 1 & 0 \\
\hline 50 & 41 & 0 & 41 & 0 & 15 \\
\hline 15 & 1 & $1(?)$ & 0 & $1(?)$ & 0 \\
\hline 15 & 6 & 6 & 0 & 1 & 0 \\
\hline 20 & 15 & 14 & 1 & 1 & 1 \\
\hline 15 & 11 & 7 & 4 & 1 & 4 \\
\hline 15 & 4 & 4 & 0 & 1 & 0 \\
\hline 15 & 2 & 2 & 0 & 1 & 0 \\
\hline 15 & 6 & 6 & 0 & 1 & 0 \\
\hline 15 & 10 & 9 & 1 & 1 & 1 \\
\hline 15 & 1 & $1(?)$ & 0 & $1(?)$ & 0 \\
\hline 15 & 4 & 3 & 1 & 1 & 1 \\
\hline 15 & 7 & 7 & 0 & 1 & 0 \\
\hline 15 & 6 & 5 & 1 & 1 & 1 \\
\hline 15 & 9 & 8 & 1 & 1 & 1 \\
\hline 30 & 24 & 23 & 1 & 1 & 1 \\
\hline 15 & 2 & 1 & 0 & 1 & 0 \\
\hline 15 & 8 & 8 & 0 & 1 & 0 \\
\hline 15 & 7 & 7 & 0 & 1 & 0 \\
\hline 15 & 10 & 10 & 0 & 1 & 0 \\
\hline 15 & 6 & 5 & 1 & 1 & 1 \\
\hline
\end{tabular}


Table 1 (continued). Received seedling populations, number of seedlings identified as nucellar and zygotic using ISSR markers, and number of retained seedlings of each type.

\begin{tabular}{|c|c|c|c|}
\hline $\begin{array}{l}\text { Lot } \\
\text { no. }\end{array}$ & $\begin{array}{l}\text { Genus, species } \\
\text { and group }\end{array}$ & Cultivar ${ }^{\mathrm{z}}$ & Source \\
\hline RS1996-035 & Citrus limonia (rangpur) & Brazilian Orange (Rangpur) & $\begin{array}{l}\text { Central Horticultural Experiment } \\
\text { Station, Chettalli, Karnataka, India }\end{array}$ \\
\hline RS1997-001 & Citrus reticulata (mandarin) & Hongju & Yunnan, PRC \\
\hline RS1997-002 & Citrus aurantium (sour orange) & Zhu Luan & Yunnan, PRC \\
\hline RS1997-003 & Citrus reticulata (mandarin) & Baiju & Yunnan, PRC \\
\hline RS1997-004 & Citrus reticulata (mandarin) & Gaojiantou Mitong & Southern Yunnan, PRC \\
\hline RS1997-005 & Citrus medica (citron) & Wild Citron & Western Yunnan, PRC \\
\hline RS1997-006 & Citrus medica (citron) & Xiangyuan & Western Yunnan, PRC \\
\hline RS1997-008 & Citrus limonia indica (?) (rangpur) & --- & Rio Farms, Monte Alto, Texas \\
\hline RS1997-009 & X Citroncirus webberii (citrange) & Etonia citrange & Rio Farms, Monte Alto, Texas \\
\hline RS1997-010 & Citrus aurantium hybrid (?)(sour orange hybrid) & Foerster mutant & Rio Farms, Monte Alto, Texas \\
\hline RS1997-011 & Citrus medica hybrid (?) (citron hybrid?) & Iran lemon & Rio Farms, Monte Alto, Texas \\
\hline RS1997-012 & Citrus sinensis (blood orange) & Mediterranean nucellar blood orange & Rio Farms, Monte Alto, Texas \\
\hline RS1997-013 & Citrus reticulata (mandarin) & Tonkan nucellar mandarin & Rio Farms, Monte Alto, Texas \\
\hline RS1998-001 & Poncirus polyandra (trifoliate) & --- & Fumin County, Yunnan, PRC \\
\hline RS1998-003 & Citrus junos (papeda hybrid) & Xiangchen & $\begin{array}{l}\text { Citrus Research Institute, Beibei, } \\
\text { Chongqing, Sichuan, PRC }\end{array}$ \\
\hline RS1998-004 & Citrus maxima (pummelo) & --- & $\begin{array}{l}\text { Citrus Research Institute, Beibei, } \\
\text { Chongqing, Sichuan, PRC }\end{array}$ \\
\hline RS1998-005 & Citrus limonia (rangpur) & Honglimeng & $\begin{array}{l}\text { Citrus Research Institute, Beibei, } \\
\text { Chongqing, Sichuan, PRC }\end{array}$ \\
\hline RS1998-006 & Citrus limonia (rangpur) & Tuningmeng & $\begin{array}{l}\text { Citrus Research Institute, Beibei, } \\
\text { Chongqing, Sichuan, PRC }\end{array}$ \\
\hline RS1998-007 & Citrus aurantium (sour orange) & Goutouchen (Goutoucheng) & $\begin{array}{l}\text { Citrus Research Institute, Beibei, } \\
\text { Chongqing, Sichuan, PRC }\end{array}$ \\
\hline RS1998-008 & Citrus reticulata (or sunki?) (sour mandarin) & Suanju & $\begin{array}{l}\text { Citrus Research Institute, Beibei, } \\
\text { Chongqing, Sichuan, PRC }\end{array}$ \\
\hline RS1998-010 & Citrus reticulata (mandarin) & Fuju & $\begin{array}{l}\text { Citrus Research Institute, Beibei, } \\
\text { Chongqing, Sichuan, PRC }\end{array}$ \\
\hline RS1998-011 & Citrus nobilis (?) (tangor) & Huangguogan & Huize, Yunnan, PRC \\
\hline RS1998-012 & Poncirus trifoliata (trifoliate) & Christiansen $4 \mathrm{~N}$ & $\begin{array}{l}\text { Whitmore Foundation Farm, } \\
\text { Groveland, Fla. }\end{array}$ \\
\hline RS1998-013 & Poncirus trifoliata (trifoliate) & Davis A & $\begin{array}{l}\text { Whitmore Foundation Farm, } \\
\text { Groveland, Fla. }\end{array}$ \\
\hline RS1998-014 & Poncirus trifoliata (trifoliate) & English Large & $\begin{array}{l}\text { Whitmore Foundation Farm, } \\
\text { Groveland, Fla. }\end{array}$ \\
\hline RS1998-015 & Poncirus trifoliata (trifoliate) & English Small & $\begin{array}{l}\text { Whitmore Foundation Farm, } \\
\text { Groveland, Fla. }\end{array}$ \\
\hline RS1998-016 & Poncirus trifoliata (trifoliate) & Gainesville 70 & $\begin{array}{l}\text { Whitmore Foundation Farm, } \\
\text { Groveland, Fla. }\end{array}$ \\
\hline RS1998-017 & Poncirus trifoliata (trifoliate) & Gainesville 71 & $\begin{array}{l}\text { Whitmore Foundation Farm, } \\
\text { Groveland, Fla. }\end{array}$ \\
\hline RS1998-018 & Poncirus trifoliata (trifoliate) & Gotha Road \#1 & $\begin{array}{l}\text { Whitmore Foundation Farm, } \\
\text { Groveland, Fla. }\end{array}$ \\
\hline RS1998-019 & Poncirus trifoliata (trifoliate) & Gotha Road \#2 & $\begin{array}{l}\text { Whitmore Foundation Farm, } \\
\text { Groveland, Fla. }\end{array}$ \\
\hline RS1998-020 & Poncirus trifoliata (trifoliate) & Kryder 25-4 & $\begin{array}{l}\text { Whitmore Foundation Farm, } \\
\text { Groveland, Fla. }\end{array}$ \\
\hline RS1998-021 & Poncirus trifoliata (trifoliate) & Kryder 43-3 & $\begin{array}{l}\text { Whitmore Foundation Farm, } \\
\text { Groveland, Fla. }\end{array}$ \\
\hline RS1998-022 & Poncirus trifoliata (trifoliate) & Large Flower & $\begin{array}{l}\text { Whitmore Foundation Farm, } \\
\text { Groveland, Fla. }\end{array}$ \\
\hline RS1998-023 & Poncirus trifoliata (trifoliate) & Large Flower (Australia) & $\begin{array}{l}\text { Whitmore Foundation Farm, } \\
\text { Groveland, Fla. }\end{array}$ \\
\hline RS1998-024 & Poncirus trifoliata (trifoliate) & Marks Small & $\begin{array}{l}\text { Whitmore Foundation Farm, } \\
\text { Groveland, Fla. }\end{array}$ \\
\hline RS1998-025 & Poncirus trifoliata (trifoliate) & Marks $1(2 \mathrm{~N})$ & $\begin{array}{l}\text { Whitmore Foundation Farm, } \\
\text { Groveland, Fla. }\end{array}$ \\
\hline
\end{tabular}




\begin{tabular}{|c|c|c|c|c|c|}
\hline \multicolumn{6}{|c|}{ Seedlings } \\
\hline Received & Germinatedy & Nucellar & Zygotic & $\begin{array}{l}\text { Nucellar } \\
\text { retained }\end{array}$ & $\begin{array}{l}\text { Zygotic } \\
\text { retained }\end{array}$ \\
\hline 15 & 11 & 10 & 1 & 1 & 1 \\
\hline 55 & 2 & 2 & 0 & 1 & 0 \\
\hline 131 & 49 & 48 & 1 & 1 & 1 \\
\hline 38 & 15 & 14 & 1 & 1 & 1 \\
\hline 82 & 26 & 22 & 4 & 1 & 4 \\
\hline 31 & 5 & 0 & 5 & 0 & 5 \\
\hline 38 & 27 & 0 & 18 & 0 & 15 \\
\hline 10 & 9 & 8 & 1 & 1 & 0 \\
\hline 30 & 27 & 27 & 0 & 1 & 0 \\
\hline 50 & 46 & 26 & 4 & 1 & 0 \\
\hline 40 & 36 & 0 & 29 & 0 & 15 \\
\hline 30 & 27 & 22 & 5 & 1 & 0 \\
\hline 20 & 10 & 7 & 0 & 1 & 0 \\
\hline 78 & 2 & 0 & 2(?) & 0 & $2(?)$ \\
\hline 70 & 1 & $1(?)$ & 0 & $1(?)$ & 0 \\
\hline 101 & 32 & 0 & 32 & 0 & 15 \\
\hline 113 & 38 & 38 & 0 & 1 & 0 \\
\hline 134 & 46 & 42 & 4 & 1 & 4 \\
\hline 109 & 38 & 35 & 3 & 1 & 3 \\
\hline 103 & 20 & 18 & 2 & 1 & 2 \\
\hline 63 & 4 & 3 & 1 & 1 & 0 \\
\hline 70 & 15 & 15 & 0 & 1 & 0 \\
\hline 29 & 22 & 16 & 4 & 1 & 0 \\
\hline 50 & 31 & 7 & 3 & 1 & 0 \\
\hline 100 & 58 & 19 & 1 & 1 & 0 \\
\hline 100 & 44 & 19 & 1 & 1 & 0 \\
\hline 100 & 32 & 20 & 0 & 1 & 0 \\
\hline 100 & 24 & 0 & $20(?)$ & 0 & 0 \\
\hline 100 & 42 & 19 & 1 & 1 & 0 \\
\hline 100 & 41 & 6 & 14 & 1 & 0 \\
\hline 100 & 23 & 14 & 6 & 1 & 0 \\
\hline 100 & 34 & 19 & 1 & 1 & 0 \\
\hline 100 & 37 & 16 & 4 & 1 & 0 \\
\hline 100 & 32 & 20 & 0 & 1 & 0 \\
\hline 50 & 45 & 14 & 6 & 1 & 0 \\
\hline 100 & 37 & 18 & 2 & 1 & 0 \\
\hline
\end{tabular}


Table 1 (continued). Received seedling populations, number of seedlings identified as nucellar and zygotic using ISSR markers, and number of retained seedlings of each type.

\begin{tabular}{|c|c|c|c|}
\hline $\begin{array}{l}\text { Lot } \\
\text { no. }\end{array}$ & $\begin{array}{l}\text { Genus, species } \\
\text { and group }\end{array}$ & Cultivarz & Source \\
\hline RS1998-026 & Poncirus trifoliata (trifoliate) & Marks 11 & $\begin{array}{l}\text { Whitmore Foundation Farm, } \\
\text { Groveland, Fla. }\end{array}$ \\
\hline RS1998-027 & Poncirus trifoliata (trifoliate) & Marks 13 & $\begin{array}{l}\text { Whitmore Foundation Farm, } \\
\text { Groveland, Fla. }\end{array}$ \\
\hline RS1998-028 & Poncirus trifoliata (trifoliate) & Rich 21-3 & $\begin{array}{l}\text { Whitmore Foundation Farm, } \\
\text { Groveland, Fla. }\end{array}$ \\
\hline RS1998-029 & Poncirus trifoliata (trifoliate) & Rich 5-2 & $\begin{array}{l}\text { Whitmore Foundation Farm, } \\
\text { Groveland, Fla. }\end{array}$ \\
\hline RS1998-030 & Poncirus trifoliata (trifoliate) & Rubidoux $1232 \mathrm{~N}$ & $\begin{array}{l}\text { Whitmore Foundation Farm, } \\
\text { Groveland, Fla. }\end{array}$ \\
\hline RS1998-031 & Poncirus trifoliata (trifoliate) & Rubidoux 123 4N & $\begin{array}{l}\text { Whitmore Foundation Farm, } \\
\text { Groveland, Fla. }\end{array}$ \\
\hline RS1998-032 & Poncirus trifoliata (trifoliate) & Rubidoux 124 & $\begin{array}{l}\text { Whitmore Foundation Farm, } \\
\text { Groveland, Fla. }\end{array}$ \\
\hline RS1998-033 & Poncirus trifoliata (trifoliate) & Small Flower & $\begin{array}{l}\text { Whitmore Foundation Farm, } \\
\text { Groveland, Fla. }\end{array}$ \\
\hline RS1998-034 & Poncirus trifoliata (trifoliate) & Small Flower No 23 & $\begin{array}{l}\text { Whitmore Foundation Farm, } \\
\text { Groveland, Fla. }\end{array}$ \\
\hline RS1998-035 & Poncirus trifoliata (trifoliate) & Swingle & $\begin{array}{l}\text { Whitmore Foundation Farm, } \\
\text { Groveland, Fla. }\end{array}$ \\
\hline RS1998-036 & Poncirus trifoliata (trifoliate) & Towne G & $\begin{array}{l}\text { Whitmore Foundation Farm, } \\
\text { Groveland, Fla. }\end{array}$ \\
\hline RS1998-037 & Citrus aurantifolia (sweet lime) & Bahman Persian \#2 & Desful, Iran \\
\hline RS1998-039 & Citrus limon? (lemon?) & India lemon & Reili County, Yunnan, PRC \\
\hline RS1998-040 & Citrus hybrid? (hybrid) & Limon pummelo & Reili County, Yunnan, PRC \\
\hline RS1998-041 & Citrus medica (citron) & Large fruited citron & Reili County, Yunnan, PRC \\
\hline RS1998-042 & Citrus limon? (lemon?) & Local lemon 2-6 & Reili County, Yunnan, PRC \\
\hline RS1998-044 & Citrus medica (citron) & Long fruited citron & Reili County, Yunnan, PRC \\
\hline RS1998-045 & Citrus medica (citron) & Small fruited citron & Reili County, Yunnan, PRC \\
\hline RS1998-046 & Citrus hybrid (hybrid) & Local lime & $\begin{array}{l}\text { Xiaochenhang, Reili County, } \\
\text { Yunnan, PRC }\end{array}$ \\
\hline RS2000-004 & Citrus aurantium (sour orange) & Corniculata & Palermo Botanic Garden (?) \\
\hline RS2000-008 & Citrus aurata (lemon?) & Pomo d'Adamo & Palermo Botanic Garden (?) \\
\hline
\end{tabular}

${ }^{2}$ As given by donor or provisionally assigned following donor's group designation.

yIn some cases, not all germinated seedlings were tested.

propagated species, accessions are maintained true-to-type by vegetative propagation, and accessions are usually heterozygous so introduction of new accessions by seed transfers genes but not elite genotypes. There are a few reports of using molecular markers in the management of perennial crops. For instance, Lopes et al. (1999) and Dangl et al. (2001) described the use of Simple Sequence Repeat (SSR) markers to verify synonyms and assess genetic diversity in grapes.

Assessment of genetic diversity in citrus using SSR markers has also been done (Barkley et al., 2003 and unpublished data). There are additional ways in which molecular markers are potentially useful in management of citrus germplasm resources (Krueger et al., 2003), one of which is to verify the genetic identity of nucellar seedlings. This would allow an earlier reduction in the number of seedlings that need to be maintained than does the traditional method of planting all seedlings in the field until fruiting. An early reduction in the number of seedlings maintained enables more efficient use of greenhouse and field resources. Although various types of markers have been developed, the inter-simple sequence repeat (ISSR) is very suitable for this use. ISSR markers use degenerate primers to reveal a large number of fragments per
PCR reaction, and thus are able to efficiently distinguish between closely related individuals (Zietkiewicz et al., 1994). In citrus, ISSR markers are well distributed over linkage groups (Roose et al., 2000; Sankar and Moore, 2001) and there is little tendency for linkage between markers amplified with a single degenerate primer. For example, $\approx 93 \%$ of those marker pairs amplified with the same primer mapped to different linkage groups (Roose et al., 2000). Therefore, use of a few ISSR primers that amplify many polymorphic markers should cover much of the genome and provide an accurate assessment of genetic identity of seedlings. ISSR markers have successfully been used in citrus to identify closely related varieties (Fang and Roose, 1997), to assess phylogenetic relationships (Fang et al., 1998), and to fingerprint and group trifoliate accessions (Fang et al., 1997). This paper reports the use of ISSR markers to identify nucellar and zygotic seedlings within received seed lots.

\section{Materials and Methods}

SEED SOURCES AND PLANTING. Seeds were received from various sources between 1996 and 2000 as indicated in Table 1. The size 


\begin{tabular}{|c|c|c|c|c|c|}
\hline \multicolumn{6}{|c|}{ Seedlings } \\
\hline Received & Germinatedy & Nucellar & Zygotic & $\begin{array}{l}\text { Nucellar } \\
\text { retained }\end{array}$ & $\begin{array}{l}\text { Zygotic } \\
\text { retained }\end{array}$ \\
\hline 100 & 31 & 20 & 0 & 1 & 0 \\
\hline 100 & 37 & 19 & 1 & 1 & 0 \\
\hline 100 & 48 & 19 & 1 & 1 & 0 \\
\hline 100 & 43 & 20 & 0 & 1 & 0 \\
\hline 100 & 22 & 20 & 0 & 1 & 0 \\
\hline 50 & 47 & 20 & 0 & 1 & 0 \\
\hline 100 & 38 & 20 & 0 & 1 & 0 \\
\hline 100 & 28 & 17 & 3 & 1 & 0 \\
\hline 100 & 28 & 20 & 0 & 1 & 0 \\
\hline 100 & 37 & 17 & 2 & 1 & 0 \\
\hline 100 & 30 & 19 & 1 & 1 & 0 \\
\hline 5 & 3 & 3 & 0 & 1 & 0 \\
\hline 55 & 21 & 0 & 15 & 0 & 15 \\
\hline 36 & 5 & 4 & 1 & 1 & 1 \\
\hline 63 & 12 & 0 & 15 & 0 & 15 \\
\hline 31 & 8 & 0 & 15 & 0 & 15 \\
\hline 27 & 16 & 0 & 16 & 0 & 15 \\
\hline 84 & 37 & 0 & 37 & 0 & 15 \\
\hline 50 & 11 & 11 & 0 & 1 & 0 \\
\hline 5 & 4 & 4 & 0 & 1 & 0 \\
\hline 5 & 2 & 2 & 0 & 1 & 0 \\
\hline
\end{tabular}

of the seed lots received varied. The cultivar names and groups are presented as supplied by the donors. Genus and species designations are presented as supplied by the donors or provisionally assigned at the Repository based upon donor comments or groupings. In some cases, corrections have been made based upon morphological characteristics of the seedlings. However, in some cases species or group assignments have not been possible, particularly when the donor has indicated that the variety is an apparent hybrid produced naturally at some time in the past.

Seed sowing and germination, and maintenance of seedling trees took place in greenhouses at the USDA-ARS National Clonal Germplasm Repository in Riverside, Calif. Seeds were retreated with 8-hydroxyquinoline sulfate as necessary when received, sown in either flats or small plastic cones, then transplanted to 3.8-L pots when of an appropriate size. The soil mix used was a modified U.C. mix of one-third sand, one-third peat moss, and one-third wood chips, supplemented at the time of mixing with micronutrients. Fertilizer was applied through the drip irrigation system and consisted of a complete commercial mix adjusted to $200 \mathrm{ppm}$ total $\mathrm{N}$ supplemented with magnesium sulfate (50 ppm) and iron chelate (20 ppm).

DNA EXTRACTION AND ISSR aNALYSIS. For seed lots coded RS1995, RS1996, and RS1997-001, RS1997-002, and RS1997-
008, total DNA was extracted from young leaves using the method of Webb and Knapp (1990) as modified by Fang et al. (1997). For the other seed lots, this protocol was extensively simplified as follows: tissue samples were sealed in fluorinated ethylene propylene (FEP) plastic bags before crushing in liquid nitrogen, the powder was extracted twice with hexadecyltrimethylammonium bromide (CTAB) precipitation buffer and then dissolved in $500 \mu \mathrm{L} 1 \mathrm{M} \mathrm{NaCl}$ as in the Webb and Knapp (1990) protocol, except that the $\mathrm{NaCl}$ solution contained $10 \mu \mathrm{g}$ of RNase A. Two volumes of $-20{ }^{\circ} \mathrm{C} \mathrm{EtOH}$ were added to the $\mathrm{NaCl}$ solution to precipitate the DNA. The pellet was washed with $65 \%$ and 85\% EtOH, dried, and resuspended in Tris-EDTA (TE) buffer. Two ISSR primers, HVH(TG)7T and HVH(CA)7T, were used for DNA amplification based upon previous work (Fang et al., 1997) that had shown them to be highly polymorphic in citrus. These primers were synthesized by Cruachem Inc. (Dulles, Va.). Each $20 \mu \mathrm{L}$ amplification reaction consisted of $10 \mathrm{~mm}$ Tris- $\mathrm{HCl}$ (pH 9.0), 50 mm KCl, 0.1\% Triton X-100, 2 mм $\mathrm{MgCl}_{2}, 200 \mu \mathrm{M}$ each dNTP, $1 \mu \mathrm{M}$ primer, $0.01 \%$ gelatin, $2 \%$ formamide, 0.05 units $/ \mu \mathrm{L}$ of $\mathrm{Taq}$ polymerase (Promega, Madison, Wis.), and 25 ng of template DNA. Amplification of seed lots coded RS1995, RS1996, and RS1997-001, RS1997-002, and RS1997-008 was performed using $20 \mu \mathrm{L}$ reactions in an Ericomp, Inc. (San Diego, 
Calif.) thermocycler as follows: 4 min at $94^{\circ} \mathrm{C}$, then 27 cycles of $30 \mathrm{~s}$ at $94{ }^{\circ} \mathrm{C}, 45 \mathrm{~s}$ at $52{ }^{\circ} \mathrm{C}$, and $2 \mathrm{~min}$ at $72{ }^{\circ} \mathrm{C}$, then a final extension for $7 \mathrm{~min}$ at $72^{\circ} \mathrm{C}$. Each reaction mixture was overlaid with $50 \mu \mathrm{L}$ of mineral oil. Amplification products were separated on $320 \times 380 \times 0.4 \mathrm{~mm} 6 \%$ nondenaturing polyacrylamide gels containing $3 \mathrm{~m}$ urea and $1 \times$ Tris-borate/EDTA (TBE) buffer at 450 V. (Zietkiewicz et al., 1994). All other seed lots were amplified in a Stratagene Robocycler (La Jolla, Calif.) using $15 \mu \mathrm{L}$ reactions and a program of $3 \mathrm{~min}$ at $94^{\circ} \mathrm{C}$, then 35 cycles of 1 min at $94{ }^{\circ} \mathrm{C}, 1 \mathrm{~min}$ at $52^{\circ} \mathrm{C}$, and $2.5 \mathrm{~min}$ at $72{ }^{\circ} \mathrm{C}$, then a final extension for $7 \mathrm{~min}$ at $72^{\circ} \mathrm{C}$. A heated lid but no oil overlay was used with this protocol. Amplification products were separated on $7 \%$ polyacrylamide (19 acrylamide : 1 bis-acrylamide) gels using denaturing conditions (8.4 M urea and 1900 V.). For all gels, DNA was detected by silver staining (Bassam et al., 1991).

Data analysis. Because only a relatively small number of seedlings was being analyzed and only two primers were used, we did not score each band in each seedling. The banding pattern generated by each primer was observed and screened visually. Accessions in which most seedlings had identical banding patterns with both primers were considered to be polyembryonic. Seedlings of these accessions with identical banding patterns were considered to be genetically identical to each other and to represent nucellar seedlings. Those with patterns differing from the nucellar pattern were considered to be zygotic seedlings. If all seedlings had different banding patterns, the seed source tree was considered monoembryonic and the individual seedlings to represent hybrid or self-pollinated individuals depending on the banding pattern. Inclusion of standard varieties within the same group as the seedlings being analyzed allowed comparison of the incoming seedlings with accessions already in the collection. This provided an initial estimation as to whether or not the

Fig. 1. Example of silver stained ISSR gel showing amplification products of primer HVH(TG)7T. Lanes 1 and 66 are size markers. Lane $2=$ 'Borneo' rangpur CRC 2424; lanes 3-6 = Rangpur RS1995-020; lanes 7-15 = Rangpur RS1997-008; lane = 16 'Borneo' rangpur; lane 17 = 'Standard' sour orange; lanes 18-27 = 'Zhu Luan' sour orange RS1997-002; lanes 28-37 = 'Foerster' mutant sour orange RS1997-010; lanes 38-40 = 'Goutoucheng' accessions CRC 4004, CRC 3929, RQ2001-004; lanes 41-43 = 'Goutoucheng' RS1998007; lane = 44 'Fuju' mandarin RQ2001-07; lane = 45 'Ponkan' CRC 3849; lanes 46-49 = 'Fuju' mandarin RS1998-010; lanes 50-53 = trifoliate oranges CRC 4008, CRC 3549, CRC 2554, CRC 3218; lanes 54-60 = trifoliate orange RS1998-013; lane 61 trifoliate orange RQ2001-010; lanes 62-65 = Poncirus polyandra RQ2001-034(2 trees) and RS1998-001 (2 seedlings). Arrows indicate zygotic seedlings.

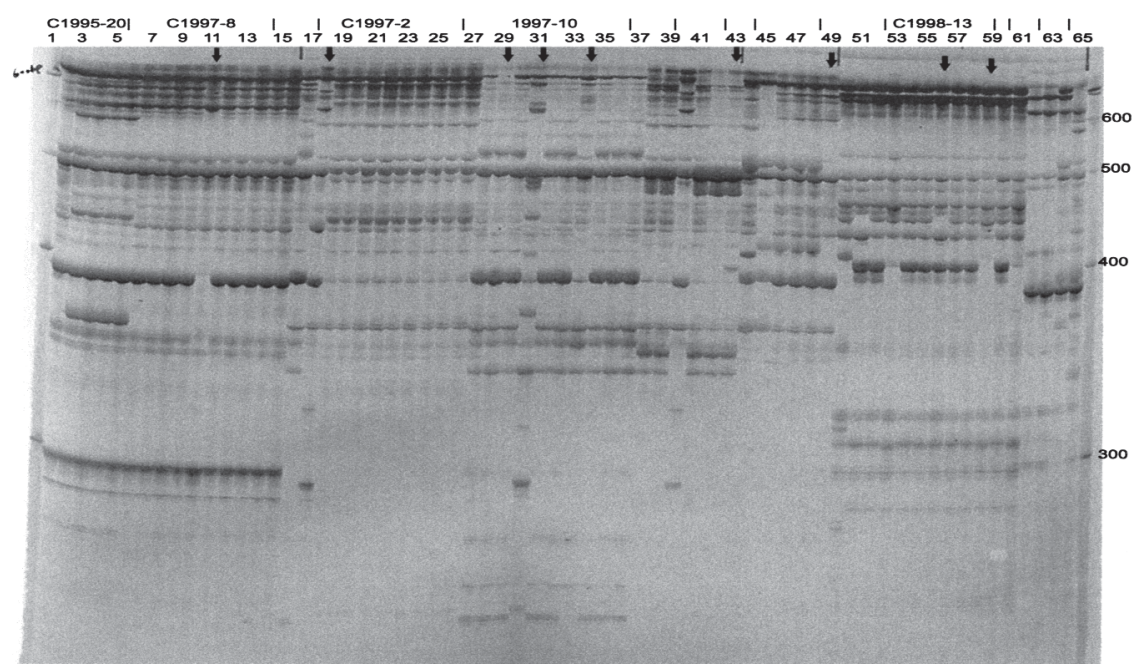

seedling would increase the genetic diversity represented in the collection.

\section{Results and Discussion}

As shown in Fig. 1, the system used produced gel images with sufficient resolution and clarity for analysis. The denaturing gels used later in the study produced sharper bands that were easier to score than those on nondenaturing gels. Each primer amplified 4 to 15 scorable bands per seedling. Nearly all bands were polymorphic among the 1340 seedlings analyzed. This polymorphism allowed the identification of nucellar seedlings as explained above. The power of the analysis was evaluated by comparing the proportion of zygotic seedlings identified with each primer. For most seed lots, $>80 \%$ of the zygotic seedlings could be identified with a single primer, indicating that two primers identified a sufficient number of polymorphic markers to distinguish nearly all zygotic seedlings. HVH(CA)7T, which produced more bands in citrus than HVH(TG)7T, was more efficient for this purpose.

For each seed lot, only one nucellar seedling was retained and the remainder was discarded as being redundant. In some cases zygotic seedlings were retained for further investigation and analysis. The seedlings identified as zygotic were generally morphologically indistinguishable from the nucellar seedlings. It is possible that subsequent flowering and fruiting would produce differences, but at this time most varieties studied are still juvenile. Even after flowering and fruiting, the genetic differences in the zygotic seedlings might not produce sufficient morphological differences to warrant them being considered different varieties or off-types. Therefore, use of this marker-based technique reduced the probability of selecting an off-type or nonrepresentative seedling as compared to using traditional selection techniques.

Visual evaluation and other traditional methods should continue to be employed in concert with molecular marker methods because the characters scored provide additional, useful information. For instance, materials introduced are sometimes misidentified or mislabeled, and therefore the fact that seedlings are identical to each other does not necessarily mean that they are the same as the named type. For example, one seed lot recently received (not discussed in this paper) was identified by the donor as a mandarin but showed trifoliate leaves. Often, misidentified seed lots are not this phenotypically different than the provided identification, and inclusion of a known standard in molecular analysis would help reduce these types of errors. However, it might not distinguish misidentified seedlings if the putative parent were similar to the actual parent. Based upon previous studies, ISSR markers generally cannot differentiate cultivars that originate by mutation (Fang and Roose, 1997) and therefore classification into groups such as navel orange vs blood orange cannot be made with markers. In addition, genotype $\times$ environment interactions will affect the phenotype of new introductions. Perhaps most importantly, many traits are not identifiable by markers or routine morphological observations. These would include such important characteristics as disease resistance, soil adaptation, etc. It is therefore imperative that both molecular and traditional evaluations continue to be carried out.

The utility of using ISSR markers to identify nucellar seedlings is demonstrated by accession 
RS1995-015-002 ('Bahman Persian lemon \#1'), which was the nucellar seedling retained from lot RS1995-015. Trees were budded from this seedling source and planted in the field for observation. The trees growing in the field have flowered and fruited for 2 years (as of Fall 2002)and have shown fruit characteristics consistent with those provided by the donor. The fact that the tree and fruit are true to type confirms that the seedling selected was nucellar and represents the type.

RANGPUR TYPES. Rangpur types (Citrus limonia Osbeck) are polyembryonic, generally producing low numbers of zygotic seedlings (Frost and Soost, 1968). The rangpurs represent one of the largest groups examined in the present study (Table 1). In total, 18 named varieties generated 222 germinated seedlings. Using the ISSR markers, the 222 seedlings were reduced to 18 nucellar seedlings representing the type. These did not appear to differ from the standard included for comparison, 'Hangleson' rangpur (PI 539344/CRC 3932). One type, 'Baishashui' (RS1995-020) appeared to differ from 'Borneo' rangpur (PI 539341/CRC 2424) (Fig. 1) and from 'Hangleson' on a different gel (not shown). There were only 13 zygotic seedlings identified in the group of 222 total seedlings and four of the zygotic seedlings originated in one lot, RS1998-006 ('Tuningmeng', ex-Sichuan PRC). The remaining nine zygotic seedlings were distributed throughout the other 17 rangpur types, with none of the other types producing more than one zygotic seedling. The 11 zygotic seedlings produced by seed received from India and China were retained for further study. Those produced by domestically-sourced seeds were not retained because the pollen parents were already present in collections.

LEMONS AND HYBRIDS. Lemons [C. limon (L.) Burm.] are apparently of hybrid origin, most probably of citron (C. medica L.) and sour orange (C. aurantium L.) (Gulsen and Roose, 2001a). As such, they are a group of relatively low diversity in the collection (Gulsen and Roose, 2001b). Many of the lemons and lemon-types found in the collection are polyembryonic, but some are monoembryonic (Frost and Soost, 1968).

Only two types in the present study could be fairly surely classed as lemons based upon morphological characteristics. Both of these, RS1995015 and RS1996-005, proved to be polyembryonic, producing only nucellar seedlings. Two varieties from Yunnan, PRC, RS1998-039 and RS1998-042, were referred to by the donor as 'possibly' being lemons or hybrids of lemons. Both of these proved to be completely monoembryonic and no selections have been made at this time. Another lot received from the same source, RS1998-040, was classified in the same way, but in this case four of the five seedlings were nucellar. One of these was retained.

Rough lemons (C. jambhiri Lush.) are a distinctive subgroup of lemon hybrids. They generally have large numbers of embryos and produce a high proportion of nucellar seedlings (Frost and Soost, 1968). The three seed lots obtained from India as rough lemons, RS1998-012, RS1998-013, and RS1998-014, were all polyembryonic and produced nucellar seedlings. Nucellar selections were made from all three lots. In addition, one zygotic seedling was retained from lot 1996-013 and, more surprisingly, four zygotic seedlings out of 11 germinated seedlings were identified in RS1998-015 and retained. This is a higher proportion of zygotic seedlings than would be expected from rough lemon types. All seedlings of rough lemon types, including the nucellars, were highly different from the standard used, 'Florida' (PI 539262/CRC 3385). These seedlings therefore represented a somewhat unexpected source of additional genetic diversity for the collection and further study and characterization are indicated.
LiMES AND HYBRIDS. Limes [C. aurantifolia (Christm.) Swing.] generally have low numbers of embryos per seed but produce few zygotic seedlings (Frost and Soost, 1968). The five lots of limes received all proved to be polyembryonic, and none produced any zygotic seedlings. One lot, RS1996-011, had only one seed germinate. This seedling could not be compared with other seedlings from the seed lot, but it did not differ from the standard employed, 'Mexican' (PI 539151/CRC 1710), so it is most probably a nucellar. None of the limes studied differed significantly from the standard type and therefore do not represent a pool of increased diversity for this group. The sweet lime, RS1998-037, produced only nucellar seedlings and did not appear to differ from the standard sweet lime (PI 37772/CRC 921).

SweEt AND SOUR ORANGES AND HYbrids. Sour oranges $(C$. aurantium $\mathrm{L}$.) and sweet oranges $[C$. sinensis $(\mathrm{L}$.) Osbeck] are probably natural hybrids between C. maxima (Burm.) Merrill and C. reticulata Blanco (Nicolosi et al., 2000). The number of embryos for these types varies from low to high, with high proportions of nucellar embryos (Frost and Soost, 1968). The few sweet oranges included in our study produced mostly nucellar seedlings.

Types classified by their donors as sour oranges or sour orange hybrids produced mostly nucellar seedlings, one of which was retained for each variety. They did not appear to differ from 'Standard' sour orange (PI 539176/CRC 628). One introduction, RS1997-10 ('Foerster') showed a somewhat higher level of zygotic seedlings (4 of 30 total) and differed from the standard on one primer pair.

One interesting result involved 'Goutoucheng'. This particular variety has been introduced several times. Two introductions as seed occurred during the 1980s, one (PI539173/CRC 4004) being from the Liuzhou Agricultural Research Institute, Guangxi, PRC, the other (PI 539170/CRC 3929) being from the Citrus Research Institute, Beibei, Chonqing, Sichuan, PRC. 'Goutoucheng' was also introduced as budwood from Beibei (RQ2001-004) in the 1980's. The seeds in the current study (RS1998-007) were also from Beibei. All three seed introductions of 'Goutoucheng' had identical markers and phenotypes, but the budwood introduction (RQ2001-04) differed from them in four bands, even though the source was the same institution as for two of the seed introductions. This result was confirmed using a second set of DNA extractions. Although it is possible that seed selections would be different than a budwood propagation from the same source, it is surprising that seed selections introduced from different sources and in some cases in different decades would be the same as each other but different than this budwood introduction. The budwood introduction RQ2001-004 has been under quarantine at different locations since its introduction in 1985. The transfer of propagative material between quarantine locations probably increased the chance of mislabeling occurring even if the identification by the donor was accurate in 1985. This is currently being investigated. It should be noted that seed lot RS1996-004 was identified as 'Gou Tou Cheng' by the donor, but classified by the donor as C. medica. Marker data and phenotype were consistent with classification as C. medica. 'Goutoucheng' refers to sour orange types and the association of this name with a citron is unusual. Because of these anomalies, RS1996-004 was not included in the comparison of 'Goutoucheng' discussed above.

MANDARINS AND MANDARIN TYPES. The germplasm commonly referred to with the general term 'mandarin' (C. reticulata Blanco) encompasses a wide range of varieties from primitive, wild types to synthetic hybrids with variable embryony (Frost and Soost, 1968). All of the six introductions identified by the donor as mandarins 
were polyembryonic and nucellar seedlings of all were kept. In a few cases, zygotic seedlings were identified and retained. Many of the mandarin types received were classified as being 'Ponkan' types and were compared with the 'Ponkan' already in the collection (PI 539523/CRC 3849). However, the nucellar types tested appeared to be different than this existing accession and so represent more than expected additional genetic diversity.

Monoembryonic Types. Pummelos [C. maxima (Burm.) Merrill.] and citrons ( $C$. medica L.) are usually monoembryonic (Frost and Soost, 1968). The three pummelos and seven citrons received all proved to be completely monoembryonic, with no identical seedlings produced. Consequently, populations of up to 15 seedlings have been planted in the field for maintenance and further observation. This number of seedlings should assure that the genes in the populations are preserved. It may or may not be possible to make a selection using traditional observational methods. It is also possible that more intensive molecular characterization and comparison with existing accessions will be useful in determining the usefulness and identity of these seedlings. One possibility would be to use the SSR markers that have been used to characterize the Citrus Variety Collection (Barkley et al., 2003 and unpublished) to assess these populations. Because most of the monoembryonic types in the UCR collection have been genotyped for SSR markers and these markers are relatively easy to compare between samples, it should be possible to determine if any of seedlings from monoembryonic types contain unique alleles. Such seedlings are also more likely to contain unique alleles at various genes and be more worthy of preservation than seedlings lacking unique alleles. The number of seedlings retained dictates that they be planted in the field rather than in the greenhouse. This compromises their phytosanitary status. The ISSR screening technique we describe here is thus less useful for managing monoembryonic types.

Papedas comprise the subgenus Papeda. Their embryony is apparently variable, with most types being monoembryonic but others possibly polyembryonic (Swingle, 1943; Frost and Soost, 1968). Only two papedas were studied. One, RS1995-018, C. hongheensis produced seedlings with unique patterns that differed from the existing accession (PI 539672/CRC 3797). The other introduction, RS1998-003, produced only one seedling, which was retained. However, whether or not this represents a nucellar is not known at this time.

Trifoliates, TRIFOLIATE TYPES, AND TRIFOLIATE HYBRIDS. The trifoliates [Poncirus trifoliata (L.) Raf.] represent a genus closely allied to Citrus. For many years this genus was considered to be monotypic, but more recently a new putative species, $P$. polyandra S.Q. Ding et al., has been published (Ding et al., 1984). $P$. trifoliata is usually described as polyembryonic (Frost and Soost, 1968), although a few monoembryonic types exist, such as 'Monoembryonic' (PI 433263/CRC 3888).

Previous work by Fang et al. (1997) with ISSR markers identified four major groups of trifoliates. One group consisted of the large-flowered accessions, and another consisted of smallflowered accessions. A third group consisted of only 'Simmons' (PI 539780/CRC 3549) and 'Monoembryonic', while the fourth small group was more divergent and consisted of accessions recently introduced from China. Their study pointed out that most of the trifoliate types available at that time were derived from a relatively narrow genetic range.

The current study examined 25 trifoliate seed lots obtained from Florida, one trifoliate obtained as budwood from Beibei, one seed lot and one budwood source of $P$. polyandra, and one citrange. The 'Etonia' citrange, RS1997-009, produced only nucellar seedlings and appeared to differ from 'Troyer' (PI 539810/CRC 1459).

The $P$. trifoliata introductions were for the most part highly nucellar and fit into the groups identified by Fang et al. (1997). The budwood introduction, RQ-2001-010, appeared to fall into the large-flower group and thus did not apparently represent any additional diversity even though it originated from PR China.

The following seed lots were identical to the large-flowered group: RS1998-012, RS1998-018, RS1998-020, RS1998-021, RS1998-022, RS1998-024, RS1998-025, RS1998-026, RS1998027, RS1998-029, RS1998-030, RS1998-031, RS1998-032, and RS1998-036. The 'small-flowered' group included: RS1998-013, RS1998-014, RS1998-015, RS1998-023, RS1998-028, RS1998033, RS1998-034, and RS1998-035. Most of these fell into the group expected from the name or existing information.

All three 'Rubidoux' introductions, 'Rubidoux $1232 \mathrm{~N}$ ' (RS1998-030), 'Rubidoux 123 4N' (RS1998-031), and 'Rubidoux 124' (RS1998-032) fell into the large-flowered group, while existing accession 'Rubidoux' (PI 539791/CRC 838) fell into the small-flowered group. CRC 838 has been derived in a direct line by vegetative propagation from the original source at the long-closed Rubidoux Experiment Station. Propagation records of the seed-source trees in Florida indicate that they have been repropagated by both seed and budwood a number of times in various locations, and it is likely that some confusion or mix up occurred. Most of the trifoliates had fairly high proportions of nucellar seedlings. However, three accessions stood out as having low proportions of nucellar seedlings. RS1998-018 and RS1998019 produced high proportions of zygotic seedlings $(70 \%$ and $30 \%$, respectively). All 20 seedlings of RS-1998-017 had unique banding patterns so it was not possible to retain a nucellar seedling as representing this type. This type may be monoembryonic. Therefore it was reintroduced as budwood.

Only two seedlings of $P$. polyandra (RS1998-001) germinated and these differed from each other (Fig. 1, lanes 64 and 65). Therefore it was not possible to identify a nucellar seedling based upon the results for this seed lot. The budwood introduction of P. polyandra (RQ2001-034) was different from both of the seedlings. It would therefore appear that the seedlings were zygotics, but this is not certain since according to the donor different varieties of $P$. polyandra exist in PRC. This species is little known, making these results difficult to interpret. However, all $P$. polyandra introductions were significantly different than any existing $P$. trifoliata accessions or introductions and therefore represent increased diversity.

\section{Literature Cited}

Barkley, N.A., M.L. Roose, and R.R. Krueger. 2003. Assessing genetic diversity in citrus by utilizing molecular markers. Proc. Intl. Soc. Citricult. IX Congr. 2000. p. 126-127.

Bassam, B.J., G. Caetano-Anolles, and P.M. Gresshoff. 1991. Fast and sensitive silver staining of DNA in polyacrylamide gels. Anal. Biochem. 196:80-83.

Bretting, P.K. and M.P. Widrlechner. 1995. Genetic markers and plant genetic resource management. Plant Breeding Rev. 13:11-86.

Dangl, G.S., M.L. Mendum, B.H. Prins, M.A. Walker, C.P. Meredith, and C.J. Simon. 2001. Simple sequence repeat analysis of a clonally propagated species: A tool for managing a grape germplasm collection. Genome 44:432-438.

Ding, S.Q., X.N. Zhang, Z.R. Bao, and M.Q. Ling. 1984. A new species of Poncirus from China. Acta Bot. Yunnanica 6:292-293.

Fang, D.Q. and M.L. Roose. 1997. Identification of closely related cit- 
rus cultivars with inter-simple sequence repeat markers. Theor. Appl. Genet. 95:408-417.

Fang, D.Q., M.L. Roose, R.R. Krueger, and C.T. Federici. 1997. Fingerprinting trifoliate orange germplasm accessions with isozymes, RFLPs, and inter-simple sequence repeat markers. Theor. Appl. Genet. 95:211-219.

Fang,D.Q.,R.R. Krueger, and M.L. Roose. 1998. Phylogenetic relationships among selected Citrus germplasm accessions revealed by inter-simple sequence repeat (ISSR) markers. J. Amer. Soc. Hort. Sci. 123:612-617.

Ford-Lloyd, B.V., M.T. Jackson, and H.J. Newbury. 1997. Molecular markers and the management of genetic resources in genebanks: A case study of rice, p. 103-118. In: J.A. Callow, B.V. Ford-Lloyd, and H.J. Newbury (eds.) Biotechnology and plant genetic resources. CAB Intl., Oxon, U.K.

Frison, E.A. and M.M. Taher. 1991. FAO/IBPGR Technical guidelines for the safe movement of citrus germplasm. Food Agr. Org. United Nations/Intl. Board Plant Genet. Resour., Rome.

Frost, H.B. and R.K. Soost. 1968. Seed reproduction: Development of gametes and embryos, p. 290-324. In: W. Reuther, L.D. Batchelor, and H.J. Webber (eds.). The citrus industry. vol. 2. Anatomy, physiology, genetics, and reproduction. rev. ed. Div. Agr. Sci., Univ. Calif., Berkeley.

Gulsen, O. and M.L. Roose. 2001a. Chloroplast and nuclear genome analysis of the parentage of lemons. J. Amer. Soc. Hort. Sci. 126:210-215.

Gulsen, O., and M.L. Roose. 2001b. Lemons: Diversity and relationships with selected Citrus genotypes as measured with nuclear genome markers. J. Amer. Soc. Hort. Sci. 126:309-317.

Krueger, R.R., O. Gulsen, and M.L. Roose. 2003. Use of molecular markers in management of citrus germplasm resources. Proc. Intl. Soc. Citricult. IX Cong. 2000. p. 167.

Lopes, M.S., K.M. Sefc, E. Eiras Dias, H. Steinkellner, M. Laimer da
Câmara Machado, and A. da Câmara Machado. 1999. The use of microsatellites for germplasm management in a Portuguese grapevine collection. Theor. Appl. Genet. 99:733-739.

Nicolosi E., Z.N. Deng, A. Gentile, S. La Malfa, G. Continella, and E. Tribulato. 2000. Citrus phylogeny and genetic origin of important species as investigated by molecular markers. Theor. Appl. Genet. 100:1155-1166.

Roose, M.L., D. Fang, F.S. Cheng, R.I. Tayyar, C.T. Federici, and R.S. Kupper. 2000. Mapping the Citrus genome. Acta Hort. 535:25-32.

Sankar,A.A. and G.A. Moore. 2001. Evaluation of inter-simple sequence repeat analysis for mapping in Citrus and extension of the genetic linkage map. Theor. Appl. Genet. 102:206-214.

Soost, R.K. and M.L. Roose. 1996. Citrus, p. 257-323. In: J. Janick and J.N. Moore (eds.) Fruit breeding. vol. 1. Tree and tropical fruits. John Wiley \& Sons, New York.

Swingle, W.T. 1943. The botany of Citrus and its wild relatives of the orange subfamily, p. 129-474. In: H.J. Webber and L.D. Batchelor (eds.) The citrus industry, vol. I. History, botany, and breeding. Univ. California Press, Berkeley, Calif.

Timmer, L.W., S.M. Garnsey, and J.H. Graham. 2000. Compendium of citrus diseases. 2nd ed. APS Press, St. Paul, Minn.

Webb, D.M. and S.J. Knapp. 1990. DNA extraction from a previously recalcitrant plant genus. Plant Mol. Biol. Rptr. 8:180-185.

Webber, H.J., W. Reuther, and H.A. Lawton. 1967. History and development of the citrus industry, p. 1-39. In: W. Reuther, H.J. Webber, and L.D. Batchelor (eds.). The citrus industry. vol. 1. History, world distribution, botany, and varieties. rev. ed. Div. Agr. Sci., Univ. Calif., Berkeley.

Zietkiewicz,E.,A. Rafalski, and D. Labuda. 1994. Genome fingerprinting by simple sequence repeat (SSR)-anchored polymerase chain reaction amplification. Genomics 20:176-183. 